\title{
Space-Time Assessment of Extreme Precipitation in Cuba between 1980 and 2019 from Multi-Source Weighted-Ensemble Precipitation Dataset
}

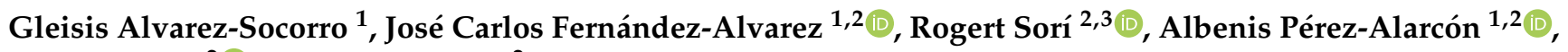 \\ Raquel Nieto ${ }^{2}$ (1) and Luis Gimeno ${ }^{2, *}$ \\ 1 Departamento de Meteorología, Instituto Superior de Tecnologías y Ciencias Aplicadas, Universidad de la \\ Habana, La Habana 10400, Cuba; gleisis1998@gmail.com (G.A.-S.); \\ jose.carlos.fernandez.alvarez@uvigo.es (J.C.F.-A.); albenis.perez.alarcon@uvigo.es (A.P.-A.) \\ 2 Centro de Investigación Mariña, Universidade de Vigo, Environmental Physics Laboratory (EPhysLab), \\ Campus As Lagoas s/n, 32004 Ourense, Spain; rogert.sori@uvigo.es (R.S.); rnieto@uvigo.es (R.N.) \\ 3 Instituto Dom Luiz, Faculdade de Ciências da Universidade de Lisboa, 1749-016 Campo Grande, Portugal \\ * Correspondence: 1.gimeno@uvigo.es
}

\section{check for}

updates

Citation: Alvarez-Socorro, G.; Fernández-Alvarez, J.C.; Sorí, R.; Pérez-Alarcón, A.; Nieto, R.; Gimeno, L. Space-Time Assessment of Extreme Precipitation in Cuba between 1980 and 2019 from Multi-Source Weighted-Ensemble Precipitation Dataset. Atmosphere 2021, 12, 995. https://doi.org/10.3390/ atmos12080995

Academic Editor: Daniel Argüeso

Received: 13 June 2021

Accepted: 29 July 2021

Published: 31 July 2021

Publisher's Note: MDPI stays neutral with regard to jurisdictional claims in published maps and institutional affiliations.

Copyright: (c) 2021 by the authors. Licensee MDPI, Basel, Switzerland. This article is an open access article distributed under the terms and conditions of the Creative Commons Attribution (CC BY) license (https:/ / creativecommons.org/licenses/by/ $4.0 /)$.

\begin{abstract}
Precipitation extremes such as heavy rainfall and floods are of great interest for climate scientists, particularly for small islands vulnerable to weather phenomena such as hurricanes. In this study, we investigated the spatio-temporal evolution of extreme rainfall over Cuba from 1980 to 2019, separating the dry and rainy periods. In addition, a ranking of extreme precipitation events was performed, which provides the number of events, the area affected, and a ranking of their magnitude by considering the magnitude of anomalies. The analysis was conducted using daily data from the multi-source weighted-ensemble precipitation (MSWEPv2). In determining the extreme precipitation ranking, the daily extreme precipitation anomaly was calculated with respect to the 95th percentile climatological distribution, giving a measure of the rarity of the event for each day and each grid point. For a more detailed analysis regarding the ranking, a separation was made by regions applying the K-mean methodology. The months belonging to the rainy period of the year presented the highest amount of precipitation above the 95th percentile compared to results obtained for the dry period. Of the six months belonging to the cyclonic season, in five of them Cuba was affected, directly or indirectly, by a tropical cyclone. The years 1982-83 and 1998 presented the highest-ranking value for the dry and rainy periods, respectively. Moreover, a trend analysis revealed an increase in the trend of occurrence of extreme events and a decrease in the percentage of the area affected. The analysis by regions showed a similar behavior to that carried out for all of Cuba. It was found that the warm phase of the ENSO events influenced approximately $\sim 22 \%$ of the occurrence of extreme events for both periods.
\end{abstract}

Keywords: extreme precipitation; ranking; MSWEP

\section{Introduction}

The study of historical and expected extreme precipitation has been of great interest in climate research and its applications due to the negative impacts it can have on the economy, the environment, and society [1-3]. Additionally, it is one of the World Climate Research Program's "grand challenge on weather and climate extremes". Although extreme precipitation involves the occurrence of high and low cumulative precipitation, the term extreme precipitation commonly refers in the literature to high cumulative rainfall in a shorter period of study. A set of 27 indices from the Climdex project (https:/ / www.climdex.org, accessed on 20 March 2021) all derived from temperature and precipitation data have been widely used to investigate the frequency and trends of extreme precipitation at global (e.g., [4,5]), regional (e.g., [6-8]), and local (e.g., [9,10]) scales for historical and future periods 
under different scenarios. The results agree that there is medium confidence that anthropogenic influences have contributed to the intensification of extreme precipitation at the global scale $[5,7,11]$, which is expected to continue under future projections [12,13]. Indeed, global warming and climate changes pose a serious threat to tropical small islands [14].

The Caribbean region experienced a positive trend of extreme rainfall according to values greater than or equal to the 95th percentile of daily precipitation (R95T) and the greatest annual five-day rainfall total (R5D) in the period from 1958 to 1999 [15]. These authors also described that these series were dominated by a strong variability of annual and decadal scales. Changes in extreme precipitation in the main islands of the Caribbean region for the period between 1961 and 2010 were also investigated by Stephenson et al. [6]. Their results showed small positive trends in annual total precipitation, daily intensity, the maximum number of consecutive dry days, and heavy rainfall events particularly during the period between 1986 and 2010. Other studies have focused on the study of extreme precipitation for certain islands of this region. Cuba, the largest island of the Caribbean, is not exempt from the occurrence and affectation of extreme precipitation events. The precipitation regime over Cuba is characterized by two main periods, the rainy from May to October and a low rainfall or dry period from November to April [3]. In the rainy period, the precipitation is related to organized rain-producing systems such as tropical waves, troughs, cyclones, and local convection, while during the dry period it is related to cold fronts, low-pressure systems, and upper cold lows [5].

Some studies have investigated the synoptic patterns and dynamics conditions associated with heavy rainfall as well as their trend for different regions of Cuba. According to Centella [16], there is a strong relationship between the precipitation variability in Cuba and large-scale circulation mechanisms associated with cold fronts, tropical waves, and the frequency of El Niño southern oscillations (ENSO) events. In addition, troughs, daily convection and instability, troughs in height, tropical storms (cyclones), and tropical lows are also meteorological systems that cause notable precipitation events (above-average monthly precipitation accumulations plus one standard deviation) in Cuba [17]. Tropical cyclones are particularly responsible for heavy rainfall events in Cuba [18] and provide a great contribution to the total annual rainfall over Cuba [19]. The identification of extreme precipitation events in the central zone of the country and the associated synoptic patterns was developed by Fernández et al. [20]. Planos [18] also studied the influence of heavy rainfall on the annual water delivery guarantee in Cuba, considering as heavy rainfall those storms in which $100 \mathrm{~mm}$ or more of rainfall accumulates in a locality during $24 \mathrm{~h}$ or less $(\mathrm{R} \times 100 \mathrm{~mm})$ during the rainy and dry periods. In addition, this author investigated the number of days with total rainfall and its distribution by intervals of different magnitudes in the western region of Cuba during the rainy and dry periods. In a more recent study, the trend for the Rx100 and the maximum consecutive five-day precipitation (Rx5day) calculated with precipitation data from nine meteorological stations located in western, central, and eastern Cuba for the period between 1971 and 2009 showed that positive trends prevailed, although most of them were not statistically significant [21]. For the second-largest island of the Cuban archipelago, the Isla de la Juventud demonstrated a generally positive trend in Rx100day, R5day, and wet days (those with accumulations above the 95th percentile (R95p)) have also been documented for the period between 1980 and 2015 [22].

Although there are some studies on the occurrence of extreme precipitation in Cuba, many of them have been carried out for specific events at regional scales, and in our search, we did not find recent studies about the temporal and spatial evolution of extreme precipitation, and particularly the assessment of extreme precipitation events. In addition, all the research on precipitation extremes in Cuba that were found and consulted for this study used extreme climate indices or fixed thresholds that only take into account the value of the precipitation intensity and how it changes over time but do not consider the area of influence, which can determine the magnitude of the real impact of the event. This factor has been considered in recent studies that have obtained a ranking of extreme precipitation 
events for the Iberian Peninsula [23,24] and Mediterranean Europe [25]. In these studies, the 95th climatological percentile is considered as a threshold to obtain the ranking of the affected area, and also the intensity of precipitation within the anomalous area to determine the magnitude of the event.

Therefore, we aim to investigate the spatio-temporal evolution of extreme precipitation in Cuba during the rainy and dry rainfall periods, and to obtain a ranking of extreme precipitation events using the methodology proposed by Ramos [24], taking into account the advantages provided by this method for the representation of the magnitude of the events. Finally, another objective is to investigate the atmospheric and dynamic conditions associated with the most anomalous precipitation events for each month during the study period (1980-2019).

\section{Region of Study}

Cuba is an archipelago in the Caribbean Sea made up of the largest island in the Caribbean Antilles called Cuba, the Isla de la Juventud (formerly called Isla de Pinos), and another 4195 keys, islets, and adjacent islands (Figure 1). It has an area of $109,884 \mathrm{~km}^{2}$ (does not include territorial waters) [26]. Due to its location in the tropical zone, very close to the Tropic of Cancer, it receives high levels of solar radiation that determines its warm climate. However, it is located on the border between the tropical and extratropical circulation zones, so it receives the influence of both on a seasonal basis with two periods already described, the rainy from May to October and the low rainfall or dry period from November to April (hereafter dry period). The bimodal character is characterized by presenting early rains in May-June-July and the greatest amount during the August-September-October, a period marked by the hurricane season [27-29].

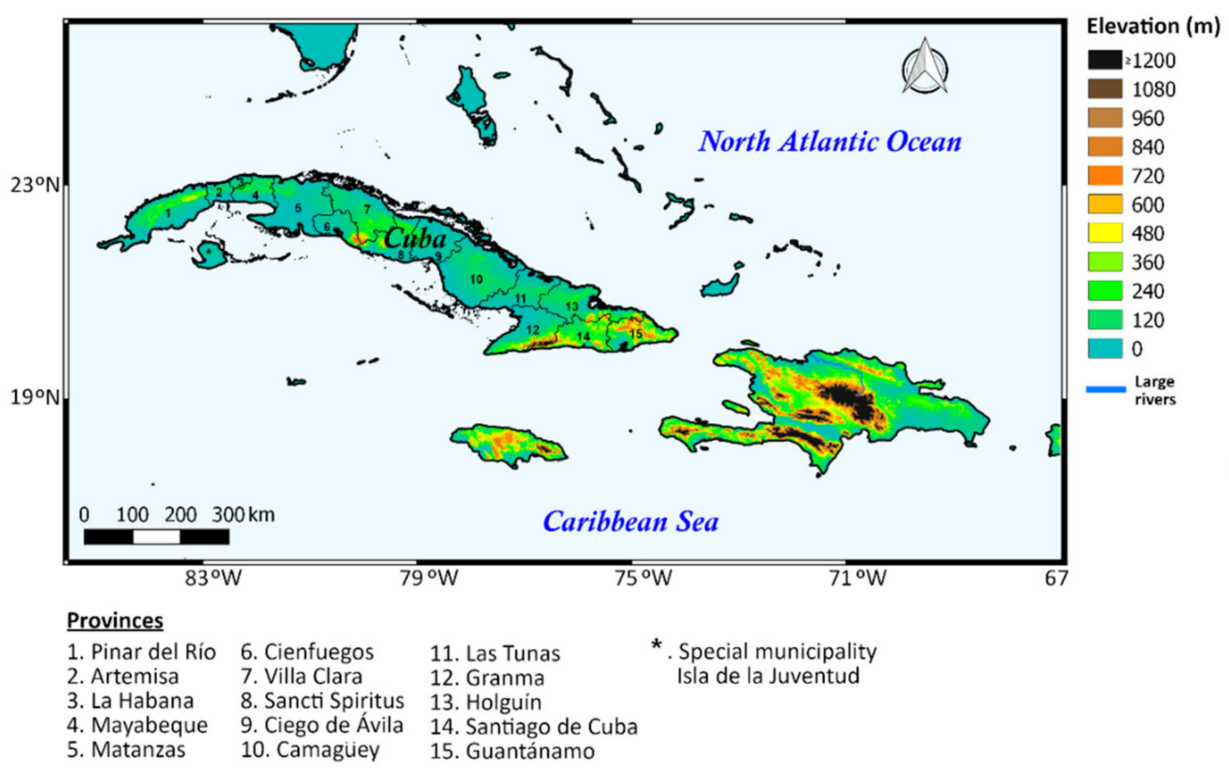

Figure 1. The geographical location of Cuba and its provinces. The elevation is shaded green-brown (in meters above sea level). The data elevation used has been downloaded from the HydroSHEDS project [30].

According to Cutié [31], the average rainfall in Cuba for the rainy period ranges between $800 \mathrm{~mm}$ and $1200 \mathrm{~mm}$, and could even reach higher values, representing $74 \%$ of the annual accumulated rainfall, while in the dry period it reaches between $200 \mathrm{~mm}$ and $600 \mathrm{~mm}$, which is equivalent to approximately $26 \%$ of the annual accumulated rainfall. The driest months are December $(38 \mathrm{~mm})$ and March $(49 \mathrm{~mm})$, and the rainiest are September $(221 \mathrm{~mm})$ and June $(218 \mathrm{~mm})$. During the winter months, Cuba is affected by cold air masses associated with the maximum influence of the extratropical circulation, which conditions a relatively dry period, while in the rainy period the North Atlantic high 
pressures predominate. The influence of the southwestern edge of this oceanic anticyclone facilitates the incursions of air flows from the south and southwest that favor rainfall, frequently linked to the establishment of a trough in the mid-tropospheric levels [32]. The trade winds and high relative humidity imposed by the North Atlantic Subtropical Anticyclone, which is the main climate modulator system for the archipelago. However, the climate is also influenced by the different physical-geographical characteristics of the national territory [32].

\section{Data and Methods}

\subsection{Data Used}

In the absence of long-term high temporal resolution precipitation data from gauging stations for Cuba, the multi-source weighted-ensemble precipitation (MSWEPv2) dataset was used [33]. This database was chosen to perform this study since it has a spatial and temporal resolution of $0.1^{\circ}$ and $3 \mathrm{~h}$, respectively, and is available for our period of study (1980-2019). The 40 years of study guarantee a sufficiently long period to evaluate the climatological spatio-temporal variability of the extreme precipitation. Besides, according to their developers, the MSWEPv2 data has been calibrated by an optimal combination of precipitation datasets from gauges' stations, satellites, and reanalysis and has been corrected the distribution biases to eliminate spurious drizzle. Additionally, the developers of this database have taken into account the systematic correction of terrestrial precipitation using 13,762 catchment records worldwide and daily observations of 76,747 gauges worldwide [33]. Specifically, the gauges, according to Beck et al. [33] have spatial coverage on land and a temporary resolution daily. In addition, in the research mentioned above, these gauges are widely distributed throughout the country, increasing their representativeness and therefore the quality of the precipitation values for Cuba. MSWEPv2 data are available online after request at www.gloh2o.org (accessed on 30 March 2021).

MSWEPv2 data are used because of its high spatial resolution, but also since it has been evaluated for the Caribbean region, showing a good performance among 16 gridded precipitation products [33]. Centella-Artola et al. [34] also described a high correspondence between precipitation from MSWEPv2 and the station data, probably reflecting the positive impact of the large number of station data used in its calibration. This is in agreement with previous evaluations performed on a global scale [35]. Although the study of CentellaArtola et al. [34] was developed for the entire Caribbean, 55\% of the observational data they used belong to stations of the Cuban National Meteorological System. That is why the evaluation of this study on the behavior of MSWEP precipitation data constitutes a reference to be considered for use in other studies for Cuba. Other studies have also used MSWEPv2 to assess the role of tropical cyclones in the total precipitation in Cuba [19].

The geopotential height (HGT) at $200 \mathrm{hPa}$ and $500 \mathrm{hPa}$, air pressure at mean sea level (MSLP), the vertical integral of northward and eastward water vapor flux, the vertically integrated moisture flux divergence (DIV-VIMF), and the total column water from the ERA5 reanalysis data [36] were used. The ERA5 is the most recent (5th generation) global atmospheric reanalysis of the European Centre for Medium-Range Weather Forecasts (ECMWF) and stands out for its high resolution $(31 \mathrm{~km}$ horizontally and 137 vertical levels), as well as for a large amount of assimilated historical observations, and represents a significant improvement over its predecessor, the ERA-Interim reanalysis. Finally, to determine the tropical cyclones (TCs) that affected Cuba in the period between 1980 and 2019, was used the Atlantic hurricane database (HURDAT2). This dataset is in text format, with information every six hours on the location, the maximum wind speed, and the minimum central pressure of all tropical and subtropical cyclones known [37]. This database is freely available from the National Hurricane Center [38]. 


\subsection{Identification of Extreme Precipitation}

To identify precipitation extremes over Cuba, the 95th percentile of the annual daily total precipitation (R95p) was used as a threshold. It returns the precipitation values where the highest $5 \%$ of precipitation values are found, corresponding to the upper tail of the precipitation distribution. This index is one of the 27 climate extremes indices offered by the Climdex project, and has been recommended by the Expert Team on Climate Change Detection and Indices (ETCCDI) for the study of climate extremes. The R95p is also one of the gridded global land in situ based data set of temperature and precipitation extremes (HadEX3) [39] and is used for the identification and spatiotemporal evolution of very wet days.

\subsection{Methodology for the Ranking of Extreme Precipitation Events}

The methodology proposed by Ramos et al. [24] was used for identifying extreme precipitation events. The method considers the value of the R95p index as a threshold for calculating anomalous days. The 95th percentile threshold is calculated for each point on the grid and for each Julian day, which ensures a correct spatiotemporal characterization of precipitation extremes. To determine the extreme precipitation ranking the first step is to calculate the daily extreme precipitation anomaly with respect to the 95th percentile climatological distribution according to Equation (1), which measures the rarity of the event.

$$
N 95_{d i j}=\text { precipitation }_{d i j}-\text { prec_95th_percentile }_{t, i, j}
$$

where $N 95_{d, i, j}$ is the extreme anomalous precipitation in the day $d$ at the grid point $(i, j)$, precipitation $_{d, i, j}$ is the daily accumulated precipitation for a particular day $d$ at the grid point $(i, j)$, and prec_95th_percentile $e_{t, i, j}$ is the Julian daily 95th percentile of the precipitation for that grid point $(i, j)$. The prec_95th percentile was calculated considering the entire reference period of data (1980-2019), but restricted to those days with meaningful precipitation, when daily precipitation registers at least $1 \mathrm{~mm}$ (wet days).

Following the same methodology, the magnitude of an extreme precipitation event is determined to establish a ranking (hereinafter $\mathrm{R}$ ) by multiplying the area (hereinafter $\mathrm{A}$, in percent) that has precipitation anomalies (N95) greater than zero, with the mean value of these anomalies (hereinafter M).

\subsection{Analysis of Extreme Precipitation Events by Regions}

A cluster analysis was applied to determine those regions with a differentiated seasonal behavior of precipitation. The objective is to characterize extreme events based on the seasonal evolution of precipitation in Cuba and its regional characteristics. The clustering procedure was performed using the $\mathrm{K}$-means method. The procedure starts with $\mathrm{k}$ random clusters, moving the objects between those clusters to minimize the variability within clusters and maximize the variability between clusters [40]. For this purpose, monthly accumulated precipitation of the rainy and dry seasons and for the period between 1980 and 2019 at each grid point over Cuba were used. In addition, for the use of the K-means method the positioning of the initial centroids was first found for the algorithm to find convergence. To achieve this, instead of working with the entire data set, random samples were selected and small runs of the method were performed to determine the initialized centroids at random. To select the optimal number of clusters $(k)$ and determine the regions into which Cuba should be divided, the Elbow graph and the Silhouette coefficient [41] were used. The Elbow plot shows at what value of k, the distance between the mean of a cluster and the other data points in the cluster is low and begins to show a change in the slope of the curve. The silhouette coefficient is a measure of the cohesion of each cluster and how well the clusters are separated [42]. The K-mean method has been also used at the Caribbean regional scale with reanalysis data for determining daily near-surface large-scale atmospheric circulation patterns over the wider Caribbean [43]. In this case, the methodology of Ramos et al. [24] was also used for the classification of extreme events. 


\section{Results}

\subsection{Analysis of Extreme Precipitation Events}

For the entire study period, 8572 extreme precipitation events (very wet days) were identified through the ranking methodology. This value was used to determine the climatological percentage of days with the occurrence of extreme precipitation events for each month with respect to the total, the result of which is shown in Figure 2. In this figure, the hydrological cycle of the precipitation is also shown. As expected, the lowest percentages were obtained for the months of the dry period $(<8 \%)$, highlighting the lowest percentage of extreme events occurring in February $(\sim 5.8 \%)$. On the contrary, in the months of the rainy period, the percentage of days with the occurrence of extreme precipitation events represents a higher percentage $(>8 \%)$ with respect to the total of events of the entire period than those identified for the dry period. In June, July, August, and September there were 3574 very wet days; the events that occurred in each month represent more than $10 \%$ of the total cases for the study period. For October and May, 800 and 753 extreme precipitation events were identified, representing $9.3 \%$ and $8.7 \%$, respectively. These results are in agreement with the marked seasonality of the rainfall in Cuba, with a period of low rainfall from November to April and a rainy period from May to October, which accumulates more than $50 \%$ of the total annual precipitation [32].

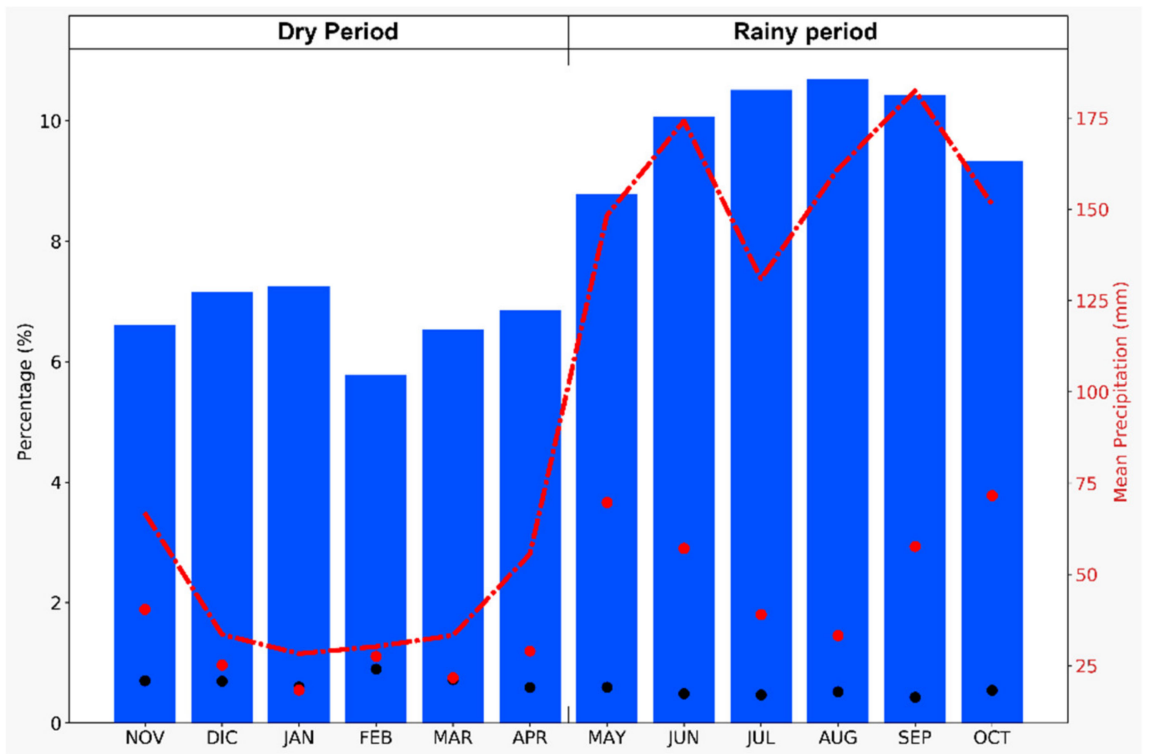

Figure 2. Monthly percentage of the number of days with precipitation above the percentile 95th respect the total extreme precipitation events (blue bars). The black and red dots show the standard deviations of this percentage and the mean precipitation for each month, respectively. Period is from 1980 to 2019.

Figure 2 also shows the standard deviations of the monthly percentage (STD_MP) and mean precipitation (STD_P) represented by black and red dots, respectively. The low STD_MP ranging between 0 to $1 \%$ during the whole hydrological year indicates that time series of percentage occurrence of extreme events during these months are normally close to the mean monthly percentages. February highlights for presenting the greater STD_MP. Contrary to what was previously described, the STD_P presents greater variation with respect to the mean values of monthly precipitation. The values range between 25 and $75 \mathrm{~mm}$, with the highest values occurring during the months of the rainy season, in correspondence with the increase in precipitation.

The total number of days for each grid point with precipitation above the 95th percentile for each month is shown in Figure 3. Figure 3a displays the frequency of occurrence for the months of the dry period. In November, the western and eastern provinces of the 
country present the highest frequencies of occurrence of extreme precipitation events (>58), while it is less frequent towards the central provinces. According to the frequency for December, the higher occurrence of extreme very wet days occurred over Guantánamo, Santiago de Cuba, and Holguín in the eastern of the country, and the north of the province Villa Clara, in the center-west of the country. January was characterized by a more homogeneous longitudinal pattern but, in general, the lowest frequencies were observed on the southern coast and the highest in the north, where consequently, the number of extreme precipitation events was higher. As for February, the highest frequency of extreme precipitation events is observed in the province of Pinar del Río, the westernmost province of the country, as well as in the north of Artemisa, Havana, Mayabeque, Matanzas, and the Isla de la Juventud. Other provinces favored by the occurrence of extreme precipitation in this month are Granma, Holguín, and Las Tunas, in the east of the country. In March the frequencies are greater than 50 across almost all the country. In April the major number of extreme events occurs in the western provinces Mayabeque, Artemisa, and part of Pinar del Rio. As for April, this is a month of transition and there is a tendency to predominate the flow from the south-southeast by the Anticyclone of the North Atlantic, allowing the transfer of humidity to the interior of the country but with greater influence on the western region. The maximum frequencies observed in the western of the country and along the northern coast can be explained by the rainfall associated with the passage of cold fronts, which move from the west to the east affecting principally the western and center of Cuba [32], weakening in their displacement.

Figure $3 b$ shows the frequency of occurrence for the months of the rainy period. In May, the maximum values are observed in the provinces of Holguín, Granma, Santiago de Cuba, and Guantánamo, while the percentages decrease towards the west. For June, the behavior is different from the previous month because now the minimum frequencies $(<50)$ are on the easternmost part of the country, in addition to finding the maximums in the range of $62-72$ and $>72$ in the provinces of Camagüey Sancti Spíritus and the south of Cienfuegos. As for July, it turned out to be the month with the lowest frequency for the entire country with values lower than 54 generally. A similar behavior showed in August but with the maximum in the province of Cienfuegos. For August, there was an increase relative to the previous month with greater frequencies in the south of the central provinces and the easternmost part of the country with values $>62 \%$. For September, the percentage turned out to be relatively higher but with the maximums on Camagüey and Matanzas and lower in the rest of the provinces. Finally, October behaves relatively similar throughout Cuba but with highs in the central region and some in the provinces of Granma, Las Tunas, and Holguín. The spatial distribution for the occurrence of extreme events denotes that the dry period shows the maximum values, with May and August standing out. In this regard, TCs play an important role since most of the cyclonic season is within the rainy period.

Taking into account the seasonal nature of precipitation in $\mathrm{Cuba}$, the frequency analysis was also carried out as a summary for the dry and rainy periods. Figure 4 shows the frequency of occurrence of events, with daily precipitation above the 95th percentile for each period. Figure 4 a corresponds to the dry period, where the maximums (57-59) are observed in the western region, mainly in its northern zone, but highlighting the provinces of Pinar del Río, Artemisa, and Havana. In addition, zones of high frequency values are observed in the provinces of Holguín, Guantánamo, and the southeast of Granma. As for the rainy period, the values are higher $(>59)$ and their distribution is different with respect to the other period. Regarding the rainy period, the frequency values are higher $(>59)$ and their spatial distribution varies compared to that described the dry period. In this period, the major frequency corresponds to the central-east region from the provinces of Cienfuegos and Sancti Spíritus to Las Tunas. It is important to clarify that this zone is relatively flat (as shown in Figure 1), which allows the convergence of the humidity flow to the interior of the country established by the convergence of the north and south breeze due to daytime warming. 


\section{(a) Dry period}

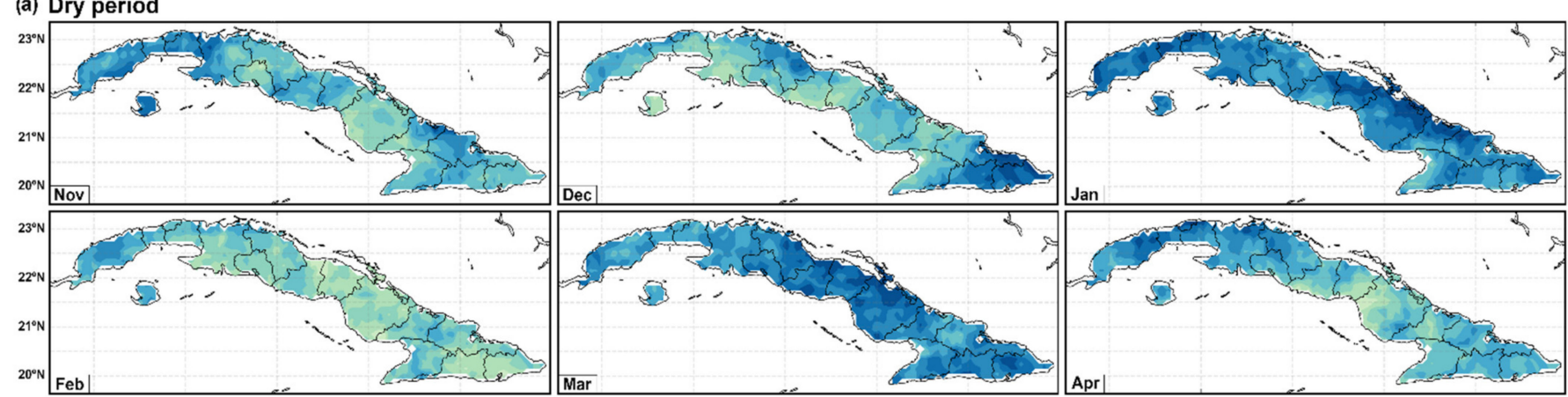

\section{(b) Rainy period}

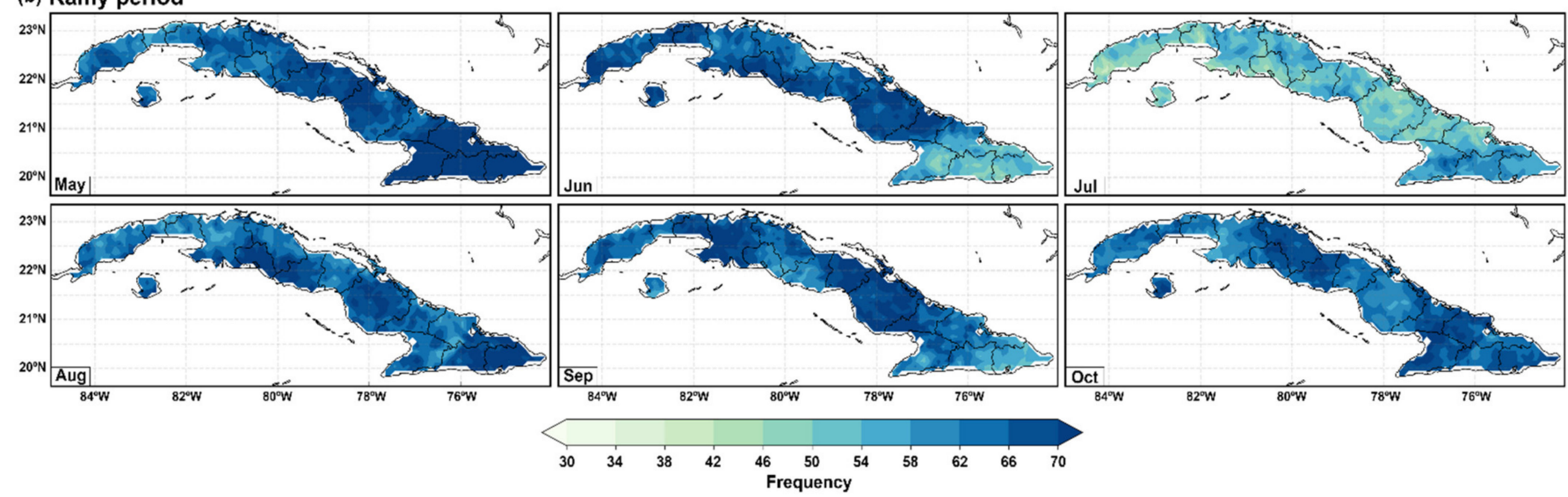

Figure 3. Monthly frequency of the number of days with daily precipitation above the percentile 95th for the months of the Dry (a) and Rainy period (b). Period from 1980 to 2019.
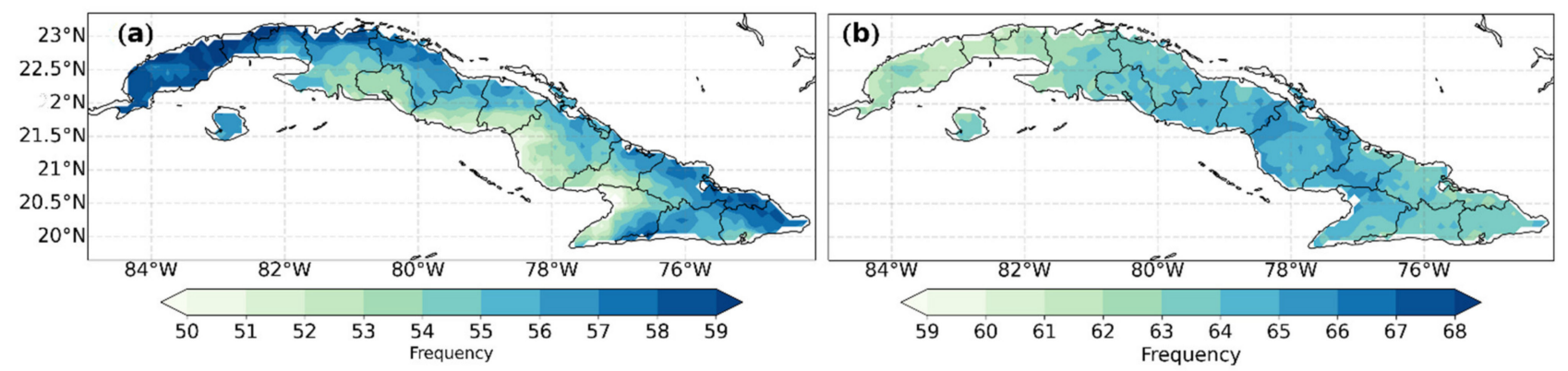

Figure 4. Mean frequency of the number of days with daily precipitation above the 95th percentile for the Dry (a) and Rainy (b) periods. Period is from 1980 to 2019.

\subsection{Ranking of Extreme Precipitation Events for Cuba}

As already commented, during the period between 1980 and 2019, a total of 8572 extreme precipitation events were identified for Cuba using the MSWEPv2 with a resolution of $0.1^{\circ}$. For a more detailed analysis, the ranking of extreme events was separated for the dry and rainy periods (Figure 5). The characteristics of the first 50 extreme precipitation events are presented in Tables S1 and S2 in the Supplementary Materials. A total of 3445 and 5127 extreme precipitation events were identified for the dry and rainy periods, respectively. The temporal evolution in the period between 1980 and 2019 of the elements $\mathrm{M}, \mathrm{A}$, and the number of extreme events (NEE) were analyzed. It is important to highlight that $\mathrm{M}$ constitutes the mean of precipitation anomaly (N95) for all the points that fulfilled the condition N95 $>0$ and A represents the percentage of points with respect to the total on the earth mask that also show values N95 $>0$. Figure 5a shows the NEE in the dry period. The series presents the maximum NEE in the periods 1981-82, 2002-03, 2011-12, 2013-14 and the minimum for 1982-83, 1991-92, and 1995-96. This series shows a positive trend of 
0.29 , which is statistically significant at $90 \%$. The range of variation is from 50 to 100 events. For the rainy period, the behavior is different since it shows a tendency $(\sim 0.67)$ to increase being statistically significant at $95 \%$. In this series, the maximum NEE occurs after 1998 and corresponds to 2001, 2003, 2005, 2007, and 2019. The minimums correspond to 1997 and 1998 (Figure 5d).

Although there has been an increase in the trend of the number of extreme precipitation events, particularly for the rainy period, the percentage of the area affected by these events has tended to decrease in both periods. However, it has been more pronounced in the dry period $\sim-0.06$ (statistically significant at 95\%) and less in the rainy period $\sim-0.02$ (statistically significant at 90\%). The percentage of area differed between both periods, showing the maximums for the dry period which ranged from $7.5 \%$ to $15 \%$, contrary to the rainy period which did not exceed $10 \%$. The maximum for the first period corresponds to $1982-83(\sim 15 \%)$ and the minimum to $2011-12(\sim 7.5 \%)$ and for the second period, 1995 obtained the maximum value of $\mathrm{A}(\sim 10 \%)$ and the minimum in $2000(\sim 6 \%)$.

The precipitation anomaly shows those values that meet the condition of being greater than the 95th percentile (see Figure $5 c, f$ ). Although only positive anomalies are expected from this analysis, it allows us to analyze the years with greater or lesser anomalies in the series of extremes of precipitation, and determine its trend. In the dry period, M shows a more pronounced oscillation in the period between 1980 and 2000, and decreases in 2019. The intervals with maximum values are presented for 1986-87 and 1993-94 ( $\mathrm{M} \sim 6 \mathrm{~mm}$ ) and the minimum for 1985-86, 1998-99, and 2016-17 ( $<3 \mathrm{~mm})$. In this case, the trend is positive but not statistically significant. For the rainy period, the trend is slightly higher compared to the other period, but it is also not statistically significant. In this case, the oscillation is more notable because higher M values are present (e.g., 2005, $\mathrm{N} 95>10 \mathrm{~mm}$ and 1988, M > $8 \mathrm{~mm}$ ). It should be noted that in these two years there are maximum values in the number of tropical cyclones that affected Cuba with twelve and seven, respectively [19]. It is important to note that although the MSWEP data do not have a high resolution, they do not have much influence on the statistical significance because Cuba has $75 \%$ of flat relief, so it is not a complex relief [44]. Therefore, it guarantees a good precipitation representation as demonstrated by Centella-Artola et al. [34].
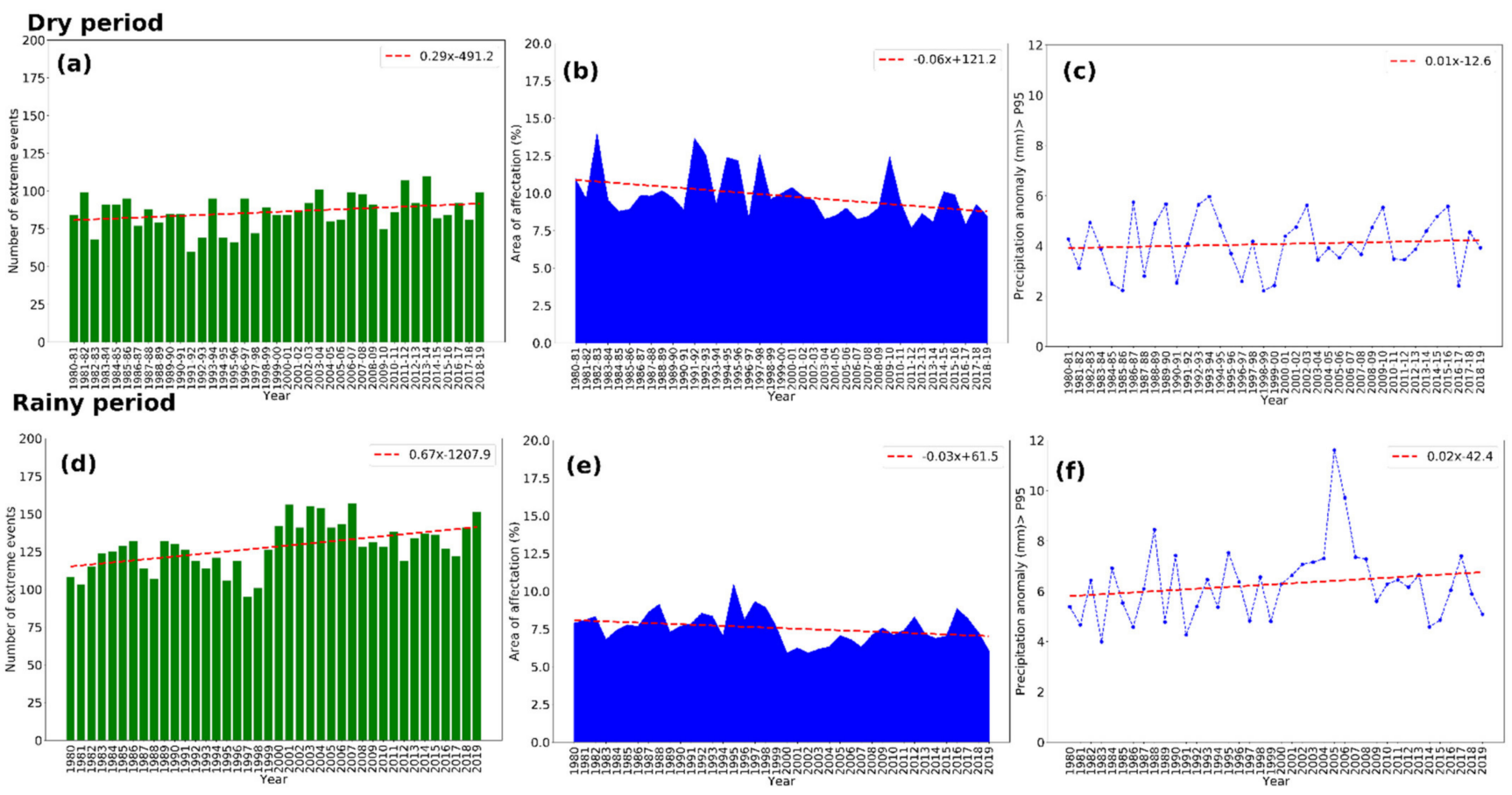

Figure 5. Number of extreme precipitation events $(\mathbf{a}, \mathbf{d})$. Area affected by extreme precipitation events expressed as percentage respect the total area of Cuba $(\mathbf{b}, \mathbf{e})$ Precipitation anomaly of $>\mathrm{P} 95(\mathbf{c}, \mathbf{f})$. The dashed red line represents the linear trend. The upper and lower row corresponds to the dry and rainy periods, respectively. Period 1980-2019. 
On the other hand, the relationship between El Niño Southern Oscillation (ENSO) and the occurrence of extreme precipitation events were analyzed. For this analysis, the Bivariate El Niño Southern Oscillation Index (BEST) [45] was used to represent the ENSO conditions. For both periods the influence of the neutral phase predominates with a percentage $(>60 \%$ ), followed by the positive phase (El Niño) with $\sim 22.07 \%$ in the dry period and slightly higher in the rainy period $(\sim 22.61 \%)$ and lastly the negative phase (La Niña) with $16.27 \%$ and $11.18 \%$ respectively (see Figure 6 ). In the dry period, the intervals with the highest NEE in the positive phase of the ENSO correspond to 1982-83, 1986-87, 1997-98, 2002-03, 2015-16, and 2018-19 periods, while in the opposite phase, the major percentage of cases are occurred in 1988-89, 2007-08, and 2010-11. In the rainy period, the years 1982, 1987, 1991, 2002, and 2015 stand out due to the strong influence of El Niño, while strong influence from La Niña prevailed in the years between 2010 and 2011. The major relationship of extreme precipitation events with El Niño may be related to the fact that warm ENSO events have a generally beneficial effect on the Caribbean climate by increasing rainfall. This is determined by a shift towards the Equator of the Subtropical Jet Stream helping the development of wet episodes in early summer [46]. In addition, the atmospheric circulation changes in the Pacific during the warm phase of ENSO [47] brings with it an anomalous behavior of winter storms that increase the frequency with which the sures, cold fronts, and prefrontal storm lines affect Cuba, causing the dry season to become rainier and sometimes stormier, mainly from January to April.
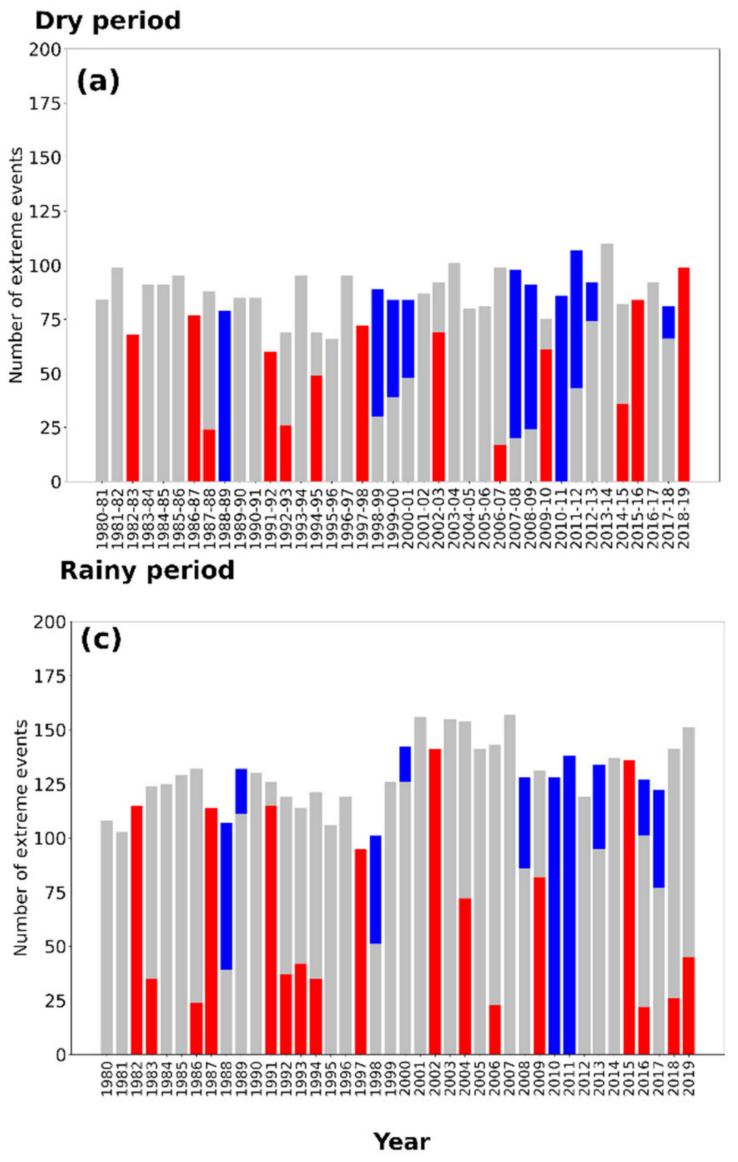

(b)

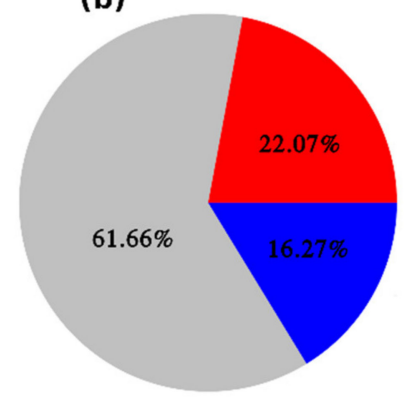

(d)

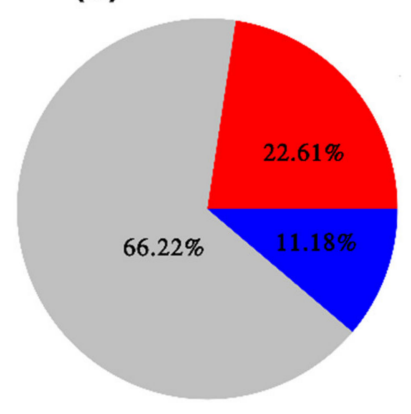

Figure 6. Left column: NEE during the different phases of ENSO: (a) Dry period and (c) rainy period. Right column: Percentage of NEE during each phase of ENSO: (b) Dry period and (d) rainy period. The colors represent the phases: red (El Niño), blue (La Niña), and gray (Neutral). Period is from 1980 to 2019.

Following the methodology of Ramos et al. [24] the area and the anomaly of the precipitation within this area was considered to compute a ranking of the extreme precipitation 
events for every season. Figure 7 shows the seasonal average of the ranking of extreme precipitation events from 1980 to 2019 for the dry and rainy periods. For this purpose, all of the days with a value in the ranking of extreme events for each month corresponding to each year were selected. Subsequently, these $\mathrm{R}$ values were averaged, obtaining the average value for the six months of each year. Then, the six values for each month were added up to determine which of the years analyzed had the highest R-value. Figure 7a shows that most of the year's present values of $200<R<800$. This implies that the values of A and $M$ averages have an order of 10 or within the interval $0-10$, being considered when analyzing an extreme event and its impact on Cuba. The period between 1982 and 1983 stand out, which presented the maximum in the values of A 15\%, followed by the period between 1991 and 92 and between 1997 and 98 with a value of $A \sim 12.5 \%$ and between 2009 and 10 with notable values in the A and $M$. In the rainy period, the mean $R(\sim 548)$ is slightly lower than in the previous period $(\sim 574)$. Likewise, the maximums that are observed are lower, in this period the year 1998 stands out, followed by 1988, 1995, 1996, 2005, and 2017. The number of TCs that affected Cuba determined this behavior except in 1998, which was characterized by extreme events with an $\mathrm{A}>7.5 \%$ as shown in Figure $5 \mathrm{e}$ and a value $>6 \mathrm{~mm}[19]$.
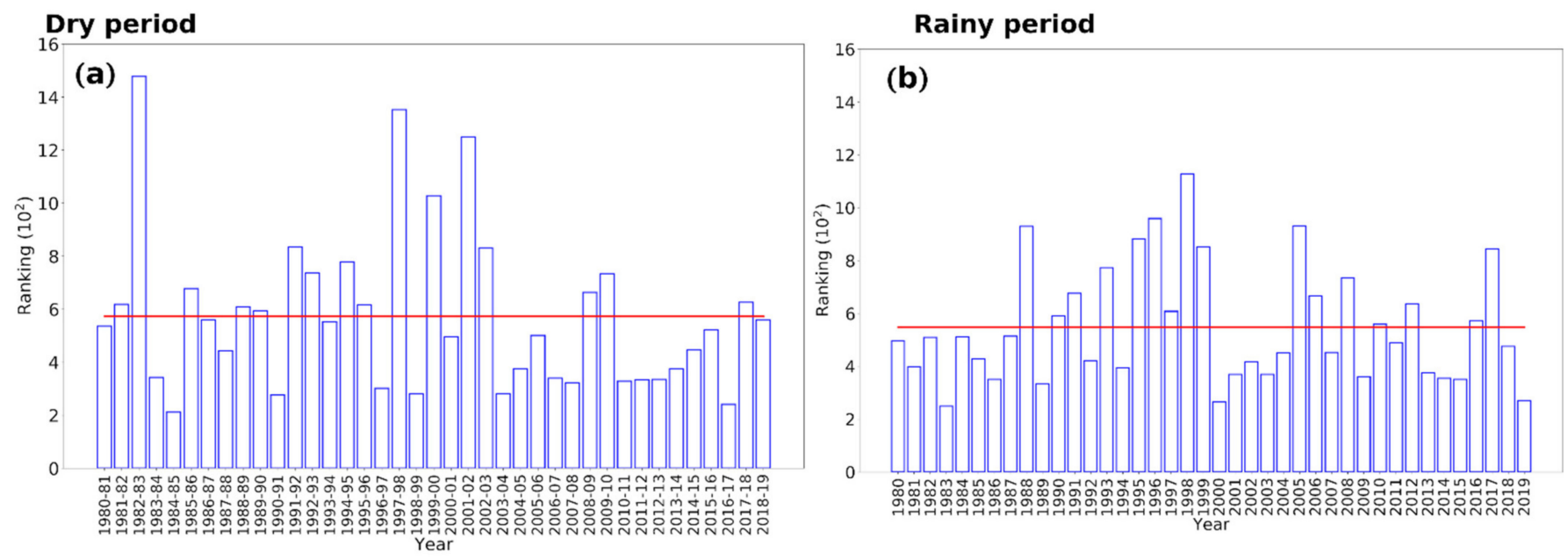

Figure 7. Mean seasonal ranking of extreme precipitation events for the dry (a) and rainy period (b). The dashed red line represents the mean ranking. Period is from 1980 to 2019.

The percentage of occurrence of extreme precipitation events by periods at each point of the grid was also analyzed in relation to the total number of extreme precipitation events determined with the methodology of Ramos et al. [24]. This is shown in Figure $8 \mathrm{a}, \mathrm{d}$. The percentages range from $\sim 3$ to $4 \%$ for the dry period, showing the maximums in the western provinces of Cuba and the provinces of Granma, Santiago, and Guantánamo ( 4-4.2\%). As can be seen in the figures, the maximum values are generally observed towards the north of the country. This can be explained by the results of Carnesoltas [48], who found the existence of convergence lines in the surface flow during the fourth stage of the breeze circulation, over the sea, to the north of the western region of Cuba. For the other period, the maximums oscillate from $4.2-4.6 \%$, mainly in the central zone of Cuba. In general, the differences in the value of the percentages are negligible, but it is important how they are distributed in each period. Furthermore, Figure $8 \mathrm{~b}$,e shows the percentage with respect to the number of days with precipitation greater than $1 \mathrm{~mm}$ (considered rainy days). In this case, the percentage showed values ranging from 2 to $2.6 \%$ (dry period) and 2.6-2.84\% (rainy period), following the same distribution mentioned above for each period, respectively. Finally, the spatial trend of extreme precipitation events was calculated. For the dry period, there was a decreasing trend in most of the country, but in certain regions, on the contrary, there was an increasing trend, mainly in the southern 
area of Matanzas. However, in the rainy season, there are positive trends in most of the country and some regions where there are no changes in general. Black dots are those that present statistically significant trends at $95 \%$. These represent that the greatest changes in each period are shown in the provinces of Cienfuegos and Sancti Spíritus and, to a lesser extent, in Artemisa and Mayabeque.
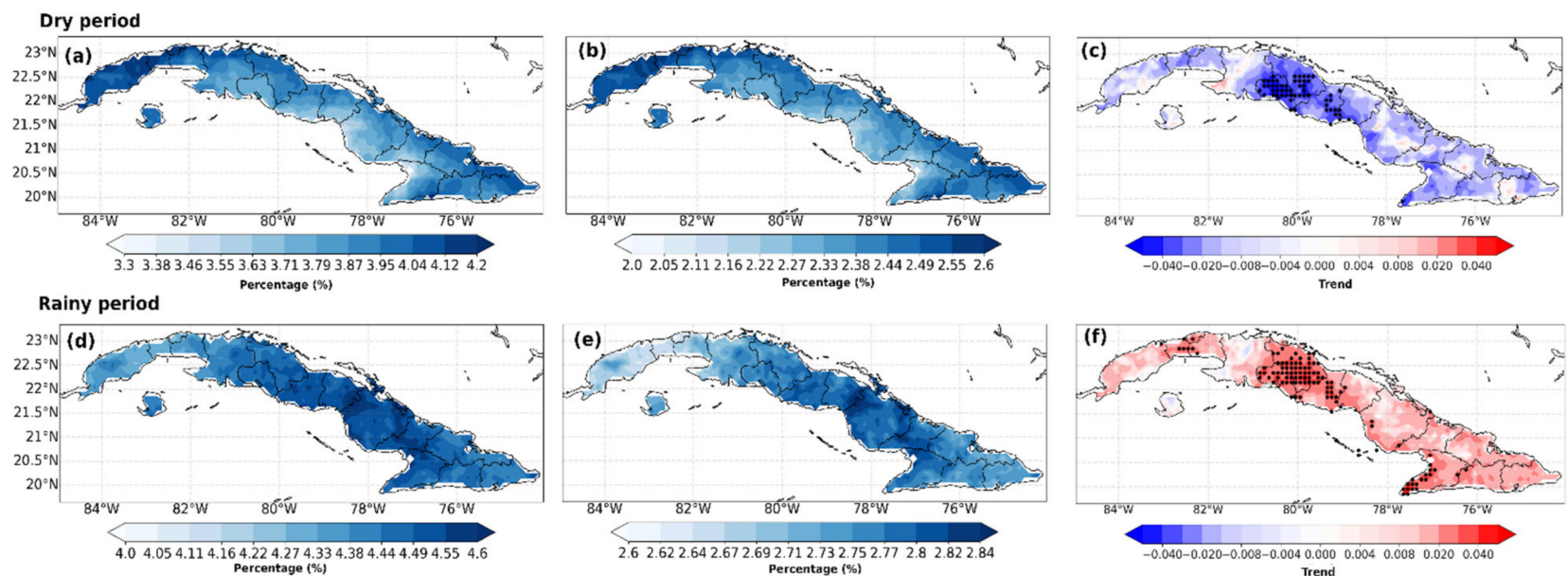

Figure 8. Percentage of occurrence of the extreme seasonal precipitation events with respect to the total number of days with extreme events $(\mathbf{a}, \mathbf{d})$. Percentage of occurrence of the extreme seasonal event with respect to the number of rainy days $(>1 \mathrm{~mm})(\mathbf{b}, \mathbf{e})$. Trend of the number of extreme precipitation events $(\mathbf{c}, \mathbf{f})$. The upper and lower row corresponds to the dry and rainy periods, respectively. Black points show statistically significant trends ( $p<0.05)$. Period 1980-2019.

Top Ranking Extreme Events for Each Month in Cuba

The top-ranked extreme precipitation event for each month during the study period was determined. Table 1 shows the date of occurrence of these events and their respective values of R, A, and M. The highest R-value was identified on 18 October 1996, in the rainy period of the year, with a value of $\sim 8271.68$, which, in turn, is the month with the highest value of $\mathrm{M}$, with $118.46 \mathrm{~mm}$. In contrast, with an $\mathrm{R}$ of $\sim 1284.57$, the month of April, corresponding to the low rainfall period of the year, turned out to be the month with the lowest value. The same also presents the second lowest value of M, with $26.09 \mathrm{~mm}$, followed by August, with $\sim 24.54 \mathrm{~mm}$, which also presents the lowest value of $\mathrm{R}$ with $\sim 1755.60$, for the months belonging to the rainy period of the year. In addition, concerning the months belonging to this last period, May and July present the other two lowest values of R, with approximately 2942.15 and 5124.93, respectively, having a behavior similar to that proposed by Lecha et al. [32], that there is an intra-summer relative minimum in the accumulated rainfall, which occurs in July and August, reflecting the bimodal character of this season.

Table 1. Top monthly extreme precipitation events in the period from 1980 to 2019.

\begin{tabular}{cccc}
\hline Date & M $(\mathbf{m m})$ & A $\mathbf{( \% )}$ & $\mathbf{R}$ \\
\hline 3 January 2003 & 35.09 & 44.10 & 1547.47 \\
3 February 1998 & 49.91 & 85.37 & 4260.82 \\
17 March 2003 & 43.88 & 73.16 & 3210.26 \\
28 April 2003 & 26.09 & 49.24 & 1284.57 \\
31 May 1993 & 34.02 & 86.48 & 2942.15 \\
1 June 1988 & 96.36 & 65.99 & 6359.44 \\
8 July 2005 & 73.71 & 69.53 & 5124.93 \\
6 August 1980 & 24.54 & 71.54 & 1755.60 \\
9 September 2017 & 85.89 & 72.45 & 6222.75 \\
18 October 1996 & 118.46 & 69.83 & 8271.68 \\
9 November 2008 & 97.03 & 52.27 & 5071.78 \\
3 December 1989 & 37.89 & 54.09 & 2049.41 \\
\hline
\end{tabular}


Regarding the A, the values ranged from $40 \%$ to $90 \%$, with the lowest value in January, with only $44.10 \%$, which also had the second lowest value of $\mathrm{R}$, at approximately 1547.47. The month of May presented the highest percentage of A, with $86.48 \%$. It is important to note that, of the 12 months of the year, 3 of them show maximum values of $R$ for January, March, and April, corresponding to the year 2003 and also to the dry period of the year.

For each of the days presented in Table 1, both the accumulated precipitation and the synoptic situation were analyzed. The former used MSWEPv2 data and the latter is represented with ERA5 reanalysis datasets, the results of which are shown in Figures 9-11. As expected, the top extreme precipitation events in the months of the rainy period show the highest accumulated rainfall, while in some of the events that occurred in the months of the dry period the precipitation doesn't affect the entire country. The event of 9 November 2008 stands out from the rest of the dry period because it occurred due to the impact of a Tropical Cyclone (TC). The cyclonic season in Cuba extends from 1 June to 30 November. On this day, Cuba was under the influence of the TC Paloma, a category 2 on the Saffir-Simpson scale with maximum winds of up to $166 \mathrm{~km} / \mathrm{h}$ and a minimum pressure of $968 \mathrm{hPa}$ at $0000 \mathrm{UTC}$ at the moment of the impact in the eastern provinces of Cuba. In its passage, it left significant accumulations of precipitation ranging between approximately $300 \mathrm{~mm}$ and $370 \mathrm{~mm}$ (see Figure 9a). The average MSLP for 9 November 2008 reveals the position of Paloma on the southern coast of Camagüey. In addition, a deepening of the low to mid-levels $(500 \mathrm{hPa})$ is observed, which favored a very well-defined structure for the circulation of the TC. This position favored the rainfall associated with the spiral bands principally over the eastern of the country. The VIMF reveals that moisture transport from the Caribbean Sea acted as a source of moisture to Paloma. Consequently, high TCW values $\left(>1400 \mathrm{~kg} / \mathrm{m}^{2}\right)$ throughout the vertical column are observed over Cuba and in most of the surrounding areas.

A visual analysis reveals that on 3 December 1989, the largest rainfall accumulation occurred in the province of Villa Clara in the central region of the country, as well as in Las Tunas, Holguín, and Granma in the eastern region, with values ranging from $\sim 120 \mathrm{~mm}$ to $150 \mathrm{~mm}$ (see Figure 9). The patterns of MSLP and HGT at $500 \mathrm{hPa}$ reveal that this event occurred due to the influence of a deep trough that is the fingerprint of a cold front associated with a low-pressure system which center is located near the $70^{\circ} \mathrm{W}$ and $42^{\circ}$ $\mathrm{N}$ (Figure 10). This system is also identified by the prevalence of moisture convergence over the half east of Cuba, which favored the upward movements and thus the cloud formation and precipitation. Consequently, the TCWV high over the central provinces of Cuba is high $\left(>1200 \mathrm{~kg} / \mathrm{m}^{2}\right)$ (Figure 10).

The extreme precipitation event of 3 January 2003, caused the highest accumulations were over the province of Matanzas in the west of the country, with maximum values ranging from approximately $120 \mathrm{~mm}$ to $150 \mathrm{~mm}$ (Figure 9). This event also occurred due to a cold front and a trough represented in the geopotential height of $500 \mathrm{hPa}$, associated with an extratropical low-pressure system located over the northeast coast of the United States (Figure 10). The TCW pattern reveals a band of maximum values extended throughout the Caribbean Sea, and influencing practically all of Cuba. The moisture flux reveals the importance of the Caribbean Sea as a source of moisture. The negative values of the VIMF divergence match the convergence associated with the cold front, which over Cuba is mostly observed from Matanzas to Ciego de Ávila.

The extreme precipitation event of 3 February 1998 (Figure 9), was induced by a low-pressure system located over the Gulf of Mexico well represented in $500 \mathrm{hPa}$ and $200 \mathrm{hPa}$ by a deep trough. This system favored the moisture transport from the Caribbean Sea to Cuba, high content of TCWV, and s strong convergence of the moisture flux over central Cuba (Figure 10). These conditions favored the intense rainfall observed over the provinces of Cienfuegos and Villa Clara ( 100 mm to $240 \mathrm{~mm})$ principally. On 17 March 2003, the weather system that caused the extreme precipitation event was a low-pressure system located in the north of the Gulf of Mexico. The synoptic situation is therefore very similar to that described for 3 February 1998. The highest daily rainfall occurred south of 
Cienfuegos and Sancti Spíritus, in the central region, and over the extreme eastern region, specifically in the provinces of Santiago de Cuba, Holguín, and Guantánamo (Figure 9). TCW values on this day were in the range of $800-1200 \mathrm{~kg} / \mathrm{m}^{2}$ for most of the national territory, as well as the prevalence of the moisture flux convergence (Figure 10).

On 28 April 2003, Cuba was under the influence of a deep trough well represented in the middle and upper-level by the HGT at $500 \mathrm{hPa}$ and $200 \mathrm{hPa}$. This situation is normally accompanied by the local ascent of the isentropic surfaces in the troposphere, which favors cooling and moistening that destabilizes the atmosphere to convection [49]. The east-southeast flow imposed by the North Atlantic anticyclonic favored the moisture transport to Cuba from the Caribbean Sea (Figure 10), which's convergence over the west of the country and isolated areas also favored the convection, the occurrence of rainfall, and the high TCWV content $\left(\sim 1200 \mathrm{~kg} / \mathrm{m}^{2}\right)$.

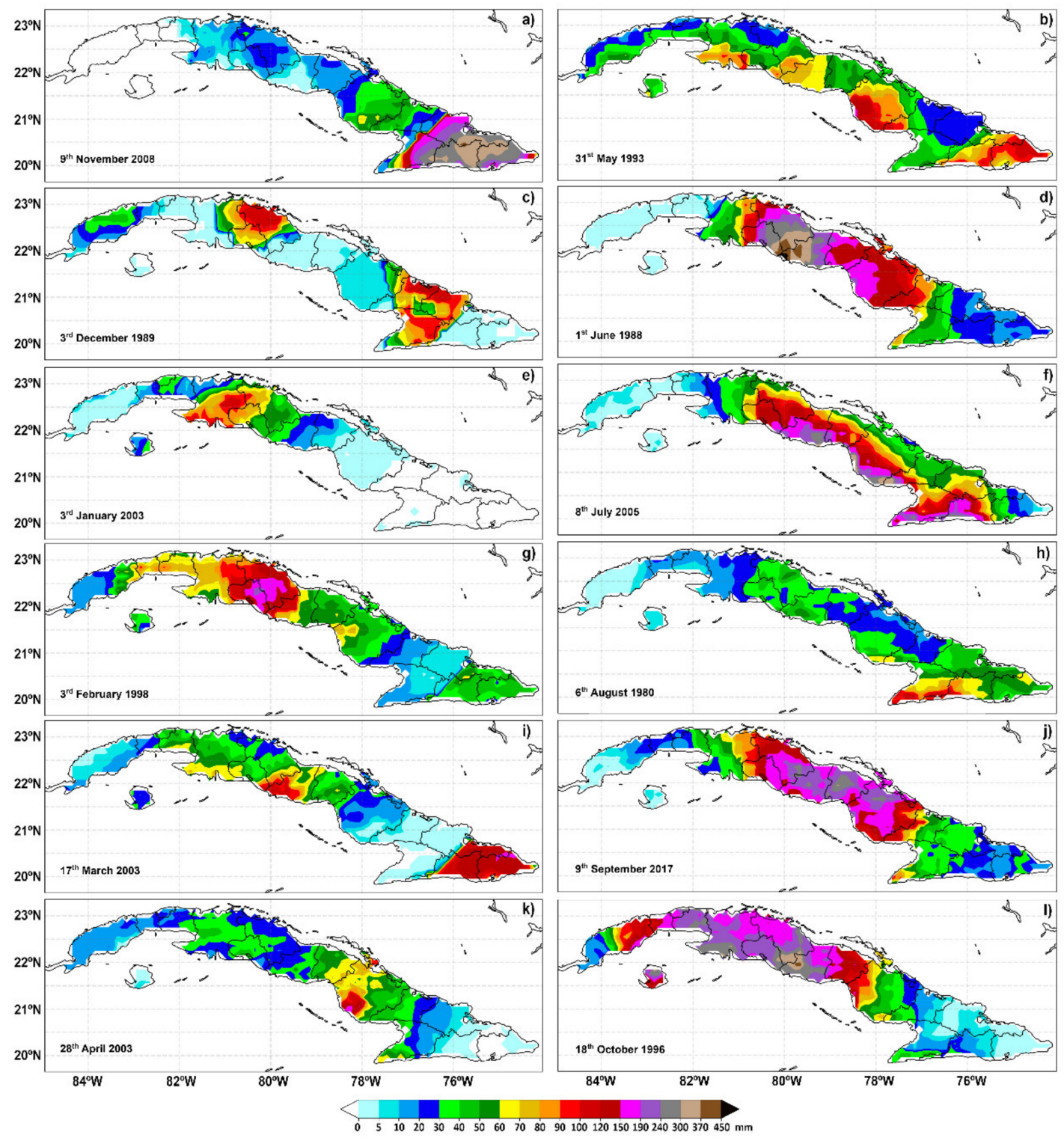

Figure 9. Precipitation pattern for the top monthly extreme precipitation events in the period from 1980 to 2019 . In the left panel are shown the months of the dry period (November-April) $(\mathbf{a}, \mathbf{c}, \mathbf{e}, \mathbf{g}, \mathbf{i}, \mathbf{k})$ and in the right panel the rainy period (May-October) (b,d,f,h, $\mathbf{j}, \mathbf{k}, \mathbf{l})$. 




Figure 10. The left column shows MSLP (shaded) and HGT at $500 \mathrm{hPa}$ (solid line) and $200 \mathrm{hPa}$ (dashed line); the central column the TCW, and the right column VIMF (arrows) and its Divergence (shaded) for every day of the top monthly ranking extreme precipitation extremes from November to April (Dry period). Period 1980-2019.

In the first month of the rainy season, on 31 May 1993, Cuba was under the influence of a low-pressure center characterized as a tropical depression and approximately located at $21.5^{\circ} \mathrm{N}$ and $84.0^{\circ} \mathrm{W}$ at $1200 \mathrm{UTC}$ (Figure 11) according to HURDAT2. This conditioned a south-southwesterly circulation over practically the entire national territory, allowing the transport of moisture from the Caribbean Sea that reach first the south of Cuba (see Figure 11). As appreciated in Figure 9, the highest rainfall (between $100 \mathrm{~mm}$ and $150 \mathrm{~mm}$ ) occurred over the south half of the country, and particularly over the south of the province Camagüey, in the central region of the country, and over the north of Guantánamo, in the eastern region. High rainfall occurred due to the intense moisture flux convergence, which favors the convection and furthers the occurrence of the precipitation. 
On 1 June 1988, a low-pressure system was moving across southern Cuba very close to the Isla of Juventud (Figure 11). The position of this system as shown in Figure 11, imposed a southerly flow, allowing the northward transport of moisture from the Caribbean Sea that later converged favoring the intense rainfall over the provinces of the central region of the country, where the rainfall ranged between approximately $370 \mathrm{~mm}$ to $450 \mathrm{~mm}$.

In the case of 8 July 2005, as can be seen in Figure 11, the highest accumulations occurred on the south coast of the central and eastern regions, reaching $\sim 370 \mathrm{~mm}$. On this day Cuba was affected by Hurricane Dennis, category 4 on the Saffir-Simpson Scale, with maximum winds of up to $240 \mathrm{~km} / \mathrm{h}$, with a minimum pressure of $938 \mathrm{hPa}$, at 1200 UTC. Figure 11 shows the approximate position of the TC and the areas of negative DIV-VIMF, respectively. On 6 August 1980, Cuba was also under the threat of another TC, in this case Allen, a hurricane category 4, with maximum winds of up to $213 \mathrm{~km} / \mathrm{h}$ and a minimum pressure of $955 \mathrm{hPa}$, at $1200 \mathrm{UTC}$. Its passage through the south of the island, left considerable accumulations, especially in the province of Granma in the eastern region, of $\sim 150 \mathrm{~mm}$. The trajectory of TC Allen through the southern-eastern provinces and its closed circulation imposed a transport of moisture from the eastern Caribbean Sea (see Figure 11).

Irma was one of the most intense hurricanes of the 2017 season. Hence September 9 of this year, was the day with the highest $\mathrm{R}$ for this month in the entire period analyzed. This system made a trajectory through the north of Cuba and the position approximately for that day can be seen in Figure 11. Figure 11 shows that considerable values for the DIV-VIMF $<0$ fields were observed. Precipitation accumulations of approximately 240 to $300 \mathrm{~mm}$ were reported, especially in the central region of the country. According to HURDAT2 reports, this hurricane reached category 5, with maximum winds of up to $268 \mathrm{~km} / \mathrm{h}$, with a minimum pressure of $924 \mathrm{hPa}$, both at 0000 and $0300 \mathrm{UTC}$.

In the last month of the rainy period of the year, Cuba was also under the influence of a TC. On 18 October 1996, the category 2 hurricane Lili, with maximum winds of up to $157 \mathrm{~km} / \mathrm{h}$ and a minimum pressure of $975 \mathrm{hPa}$, both at 0930 and at $1200 \mathrm{UTC}$, affected the western and central regions of the island, leaving a maximum accumulated rainfall of approximately 370 to $450 \mathrm{~mm}$ in the province of Sancti Spíritus. Figure 11 shows the position of this TC south of Cuba, imposing a circulation over the Caribbean Sea dragging all of the moisture towards the Cuban territory. As for this period, the TCW had very similar behavior in most of the days, since the maximum values $\sim 1600-1800 \mathrm{~kg} / \mathrm{m}^{2}$, are located in the central region of the TC that affected Cuba by the strong convection. This is a characteristic of these tropical systems that they present near the wall of the eye when they are systems with a higher intensity showing a ring of cumulonimbus convection [50]. For the case of 31 May 1993 and 1 June 1988, there is greater dispersion in the TCW field since the systems are very weak and in general the bands of more intense rains extend far from the center and present the maximum TCW that precisely extend over the national territory (see Figure 11).

\subsection{Ranking of Extreme Precipitation Events by Regions}

For a more detailed analysis of extreme events, a regionalization of the precipitation in Cuba was carried out applying the K-mean methodology. This allowed determining the optimal number of clusters for Cuba. Figure 12a,b show the three regions selected (R1, R2, and R3). For this selection, the Elbow plot criterion was used. As can be seen in Figure $12 c, d$, the changes in the slopes of the curves are shown for three clusters forward, showing that the distance between the center of the cluster and the other points belonging to it begin to decrease. Additionally, to check the correct choice of k, the Silhouette coefficient was used; it returns the cohesion of a cluster and its separation with respect to the other clusters. As can be seen, it is notable that for two and three clusters, the maximum values are reached (see Figure 12e,f), being higher than 0.40 (fair solution according to CorporalLodangco et al. [42]). Therefore, $\mathrm{k}=3$ was selected for both periods. The main differences between the point distributions for each region are presented from Cienfuegos and Sancti Spíritus provinces to Las Tunas. 


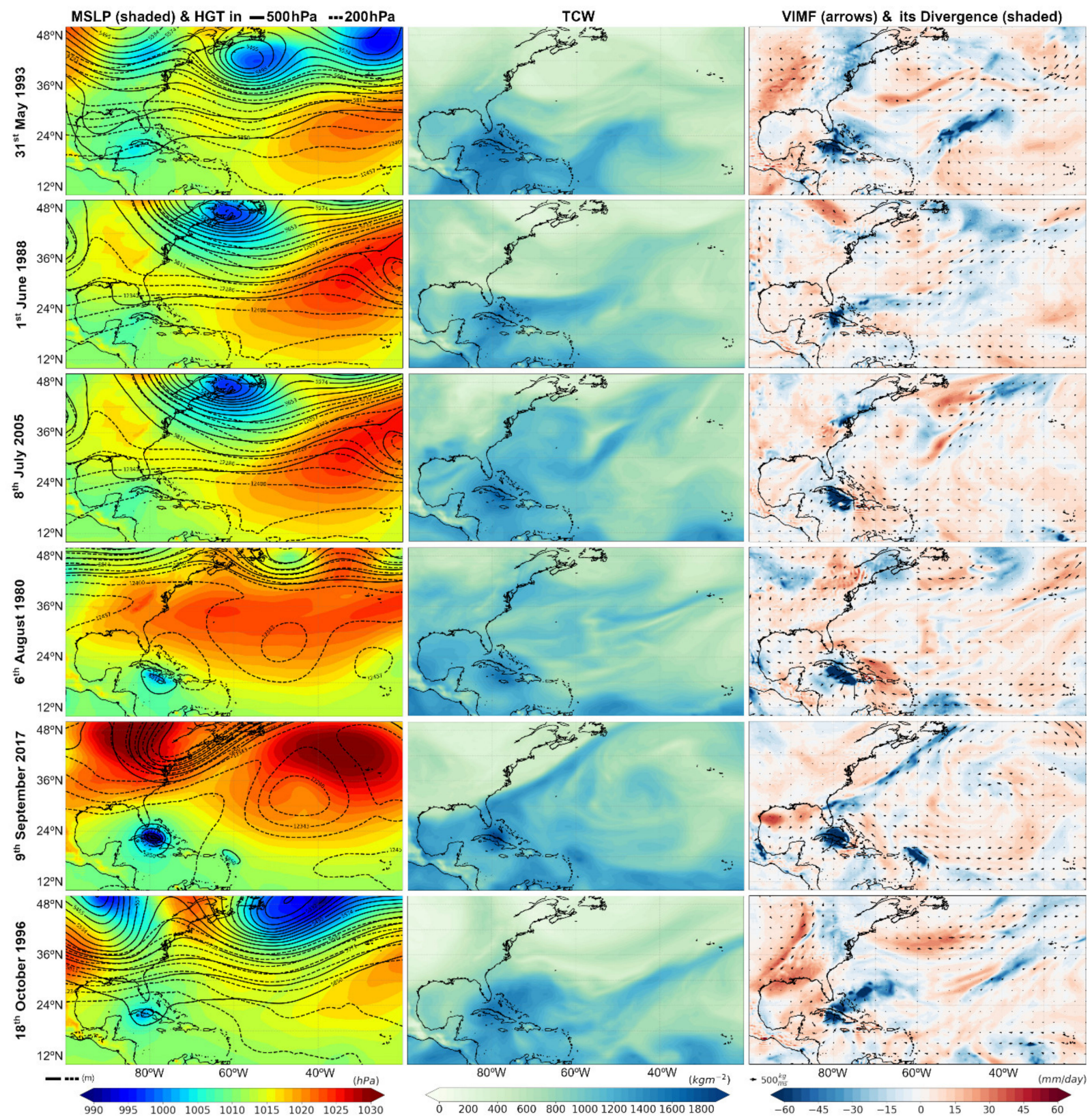

Figure 11. As Figure 10 but for May to October (Rainy period).

Once the regions with differentiated precipitation behavior within Cuba were identified, the methodology of Ramos et al. [24] was used to determine the total number of extreme precipitation events in each region, as well as the parameters NEE, A, and M, whose trend was investigated. The results are presented in Table 2 . The total of extreme events was higher for R1, followed by R2 and R3 in the dry period. This behavior is mainly attributed to the fact that these months the frontal systems coming from the middle latitudes impact with greater intensity the western zone of Cuba and they weaken towards the east of the country. It can be seen that there is a positive trend for NEE per year in the three regions but with a higher value for R2 (statistically at 90\%). Regarding A, there are negative but very similar trends for the three regions but only statistically significant at 95\% for R1 and R2. The trend for M is more noticeable in R3, being decreasing unlike R1 and R3, but with little difference between all of them. 

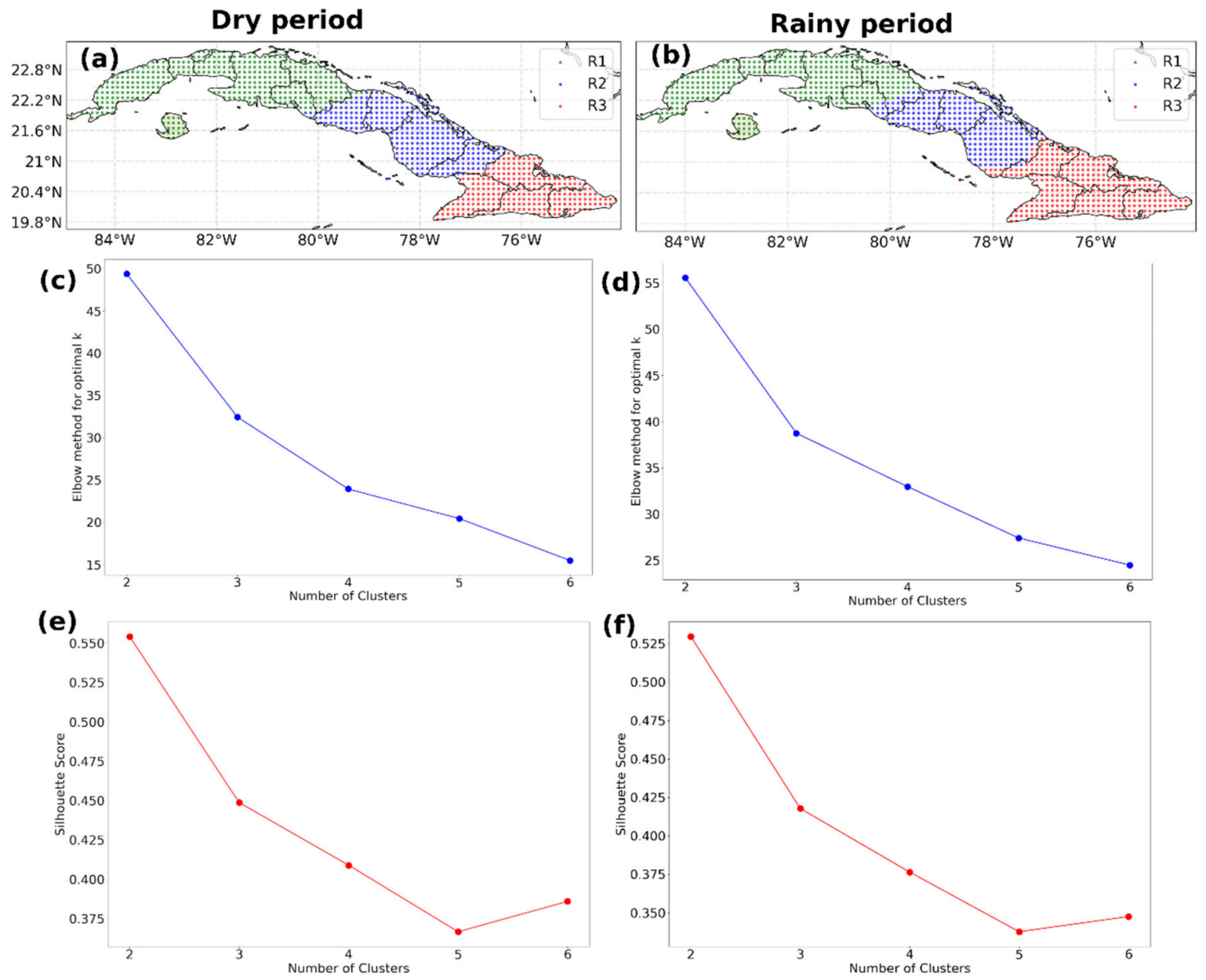

Figure 12. Regions obtained from the cluster analysis for the dry (a) and rainy (b) periods. The criteria used for the selection of the optimal number of $k$. Elbow plot $(\mathbf{c}, \mathbf{d})$. Silhouette coefficient $(\mathbf{e}, \mathbf{f})$.

Table 2. Total number of extreme events and trend of the ranking elements for each region. The percentage shows the level of statistical significance. Dry and rainy periods (1980-2019).

\begin{tabular}{ccccccc}
\hline Elements & R1 (Dry Period) & R2 (Dry Period) & R3 (Dry Period) & R1 (Rainy Period) & R2 (Rainy Period) & R3 (Rainy Period) \\
\hline Total of NEE & 5682 & 5227 & 4914 & 5574 & 4707 & 5637 \\
\hline Trend of NEE per year & 0.16 & $0.25(90 \%)$ & 0.11 & 0.78 & 0.38 & $0.77(95 \%)$ \\
\hline Trend of A per year & $-0.08(95 \%)$ & $-0.12(95 \%)$ & -0.08 & $-0.07(95 \%)$ & -0.05 & $-0.07(90 \%)$ \\
\hline Trend of M per year & 0.01 & 0.01 & -0.02 & 0.03 & $0.03(95 \%)$ & 0.01 \\
\hline
\end{tabular}

For the rainy season, R3 presents the highest NEE with 5637, followed by R1 5574 and to a lesser extent R3. This result shows similarity with the percentage presented in Figure 8 for each period. The NEE trends are positive but only statistically significant at $95 \%$ for R3 ( 0.77), the opposite is the behavior for A since it tends to decrease with the maximum values for R1 and R3 at 95\% significance. Finally, the trends are positive for M from 0.01 to 0.05 per year but only for R2 with a significance level of $95 \%$.

\section{Conclusions}

In this study, the spatio-temporal characteristics of extreme precipitation in Cuba during the period between 1980 and 2019 were investigated. Likewise, a ranking of extreme precipitation events and a regionalization of precipitation were carried out for the analysis of extreme events, taking into account the separation by dry and rainy periods. From the spatial point of view, it was found that for the dry period the highest number of 
extreme precipitation events is observed in the western region, mainly in the northern area and in an eastern portion of the country. For the rainy period, the values are higher and their distribution varies with respect to the other period. For the rainy period, the values are higher and their distribution varies with respect to the other period. In this case, the maximums correspond to the central region from the provinces of Cienfuegos and Sancti Spíritus to Las Tunas and Camagüey.

During the study period, a total of 8572 extreme precipitation events were identified. This result is determined by the high resolution $\left(0.1^{\circ}\right)$ of the MSWEPv2 precipitation data utilized here. In the dry and rainy periods, there were 3445 and 5127 extreme precipitation events, respectively. Annually, the trend of occurrence of extreme events in Cuba, the percentage of the area affected by such events, as well as the precipitation that meets the condition of being above the R95p (precipitation extremes), were also analyzed each period. It was found that the NEE shows a positive trend of 0.29 and $0.67 \mathrm{NEE} / \mathrm{year}$ for the dry and rainy periods respectively. Contrary was the trend shown for A, being negative in both periods but very different behavior presented the anomaly since it does not have a statistically significant trend. In addition, it was found that the warm phase of the ENSO events influenced approximately $22 \%$ in the occurrence of extreme events for both periods.

On the other hand, the analysis by regions showed similar results to the one carried out for the whole country, but with greater importance for R2 in the dry season (since it presents the greatest positive trend towards an increase in NEE and a decrease in A). What is different is the behavior presented for the rainy season, since R3 presents the highest number of events and a statistically significant positive trend to increase at $95 \%$. In addition, for the top-ranking extreme precipitation event of each month, both the accumulated daily precipitation and the synoptic and dynamics conditions were analyzed. The results show that the highest accumulated precipitation in Cuba, in a range of $\sim 370$ to $450 \mathrm{~mm}$, was due to the influence of TCs. The top-ranking extreme precipitation event in five of the six months of the cyclonic season was caused by a TC, which confirms the crucial role of these phenomena as ready described by numerous studies. On the other hand, in the dry period, the passage of low-pressure systems to the east through the North Atlantic storm track determined in four months the maximum $\mathrm{R}$ values, different from November, which was under the influence of the TC Paloma. Future research will study the sources of moisture that contribute to the moisture supply of these extreme events in both periods, and the role that each one plays will be studied.

Supplementary Materials: The following is available online at https:/ /www.mdpi.com/article/10 .3390 /atmos12080995/s1. Table S1: Ranking of the first 50 extreme precipitation events for the dry period (1980-2019); Table S2: Ranking of the first 50 extreme precipitation events for the rainy period (1980-2019).

Author Contributions: G.A.-S., J.C.F.-A., R.S., R.N., and L.G. conceived the idea of the study. G.A.-S., J.C.F.-A., R.S. and A.P.-A. processed the data and created the figures. G.A.-S., J.C.F.-A. and R.S. analyzed the results and wrote the manuscript. All authors analyzed the results and revised the manuscript. All authors have read and agreed to the published version of the manuscript.

Funding: EPhysLab receives partial support from the Xunta de Galicia under the Project ED431C 2021/44 (Programa de Consolidación e Estructuración de Unidades de Investigación Competitivas (Grupos de Referencia Competitiva) and Consellería de Cultura, Educación e Universidade).

Institutional Review Board Statement: Not applicable.

Informed Consent Statement: Not applicable.

Acknowledgments: J.C.F.-A. and R.S. acknowledge the support from the Xunta de Galicia (Galician Regional Government) under the grants no. ED481A-2020/193 and ED481B 2019/070, respectively. A.P.-A. acknowledges the support from UVigo PhD grants. We gratefully acknowledge the Princeton Climate Laboratory for freely providing the MSWEP dataset.

Conflicts of Interest: The authors declare no conflict of interest. 


\section{References}

1. Handmer, J.; Honda, Y.; Kundzewicz, Z.W.; Arnell, N.; Benito, G.; Hatfield, J.; Mohamed, I.F.; Peduzzi, P.; Wu, S.; Sherstyukov, B.; et al. Changes in impacts of climate extremes: Human systems and ecosystems. In Managing the Risks of Extreme Events and Disasters to Advance Climate Change Adaptation; Field, C.B., Barros, V., Stocker, T.F., Qin, D., Dokken, D.J., Ebi, K.L., Mastrandrea, M.D., Mach, K.J., Plattner, G.-K., Allen, S.K., et al., Eds.; A Special Report of Working Groups I and II of the Intergovernmental Panel on Climate Change (IPCC); Cambridge University Press: Cambridge, UK; New York, NY, USA, 2012; pp. $231-290$.

2. Bell, J.E.; Langford, C.; Conlon, K.; Herring, S.; Kunkel, K.E.; Lawrimore, J.; Luber, G.; Schreck, C.; Smith, A.; Uejio, C. Changes in extreme events and the potential impacts on human health. J. Air Waste Manag. Assoc. 2018, 68, 265-287. [CrossRef] [PubMed]

3. Liu, Y.; Chen, J.; Pan, T.; Liu, Y.; Zhang, Y.; Ge, Q. Global socioeconomic risk of precipitation extremes under climate change. Earth's Future 2020, 8, e2019EF001331. [CrossRef] [PubMed]

4. Alexander, L.V. Global observed changes in daily climate extremes of temperature and precipitation. J. Geophys. Res. 2006, 111, D05109. [CrossRef]

5. Papalexiou, S.M.; Montanari, A. Global and regional increase of precipitation extremes under global warming. Water Resour. Res. 2019, 55, 4901-4914. [CrossRef]

6. Stephenson, T.S.; Vincent, L.A.; Allen, T.; Van Meerbeeck, C.J.; McLean, N.; Peterson, T.C.; Taylor, M.A.; Aaron-Morrison, A.P.; Auguste, T.; Bernard, D.; et al. Changes in extreme temperature and precipitation in the Caribbean region, 1961-2010. Int. J. Climatol. 2014, 34, 2957-2971. [CrossRef]

7. Myhre, G.; Alterskjær, K.; Stjern, C.W. Frequency of extreme precipitation increases extensively with event rareness under global warming. Sci. Rep. 2019, 9, 16063. [CrossRef] [PubMed]

8. Zhang, W.; Zhou, T. Significant increases in extreme precipitation and the associations with global warming over the global land monsoon regions. J. Clim. 2019, 32, 8465-8488. [CrossRef]

9. Li, W.; He, X.; Scaioni, M.; Yao, D.; Mi, C.; Zhao, J.; Chen, Y.; Zhang, K.; Gao, J.; Li, X. Annual precipitation and daily extreme precipitation distribution: Possible trends from 1960 to 2010 in urban areas of China. Geomat. Nat. Hazards Risk 2019, 10, 1694-1711. [CrossRef]

10. Mahjabin, T.; Abdul-Aziz, O.I. Trends in the magnitude and frequency of extreme rainfall regimes in Florida. Water 2020, $12,2582$. [CrossRef]

11. Seneviratne, S.I.; Nicholls, N.; Easterling, D.; Goodess, C.M.; Kanae, S.; Kossin, J.; Luo, Y.; Marengo, J.; McInnes, K.; Rahimi, M.; et al. Changes in climate extremes and their impacts on the natural physical environment. In Managing the Risks of Extreme Events and Disasters to Advance Climate Change Adaptation; Field, C.B., Barros, V., Stocker, T.F., Qin, D., Dokken, D.J., Ebi, K.L., Mastrandrea, M.D., Mach, K.J., Plattner, G.-K., Allen, S.K., et al., Eds.; A Special Report of Working Groups I and II of the Intergovernmental Panel on Climate Change (IPCC); Cambridge University Press: Cambridge, UK; New York, NY, USA, 2012; pp. 109-123.

12. Kitoh, A.; Endo, H. Changes in precipitation extremes projected by a $20-\mathrm{km}$ mesh global atmospheric model. Weather Clim. Extrem. 2016, 11, 41-52. [CrossRef]

13. Kirchmeier-Young, M.C.; Zhang, X. Human influence has intensified extreme precipitation in North America. Proc. Natl. Acad. Sci. USA 2020, 117, 13308-13313. [CrossRef]

14. Nurse, L.A.; McLean, R.F.; Agard, J.; Briguglio, L.P.; Duvat-Magnan, V.; Pelesikoti, N.; Tompkins, E.; Webb, A. Small islands. In Climate Change 2014: Impacts, Adaptation, and Vulnerability. Part B: Regional Aspects; Contribution of Working Group II to the Fifth Assessment Report of the Intergovernmental Panel on Climate Change; Barros, V.R., Field, C.B., Dokken, D.J., Mastrandrea, M.D., Mach, K.J., Bilir, T.E., Chatterjee, M., Ebi, K.L., Estrada, Y.O., Genova, R.C., et al., Eds.; Cambridge University Press: Cambridge, UK; New York, NY, USA, 2014; pp. 1613-1654.

15. Peterson, T.C. Recent changes in climate extremes in the Caribbean region. J. Geophys. Res. 2002, 107, 4601. [CrossRef]

16. Centella, A. Variabilidad y Cambios del Clima en Cuba; Reporte Técnico del Instituto de Meteorología: La Habana, Cuba, 1998.

17. Gómez-Villa, Y.; Álvarez-Escudero, L.; Centella-Artola, A.D.; Pérez-Suárez, R.; Borrajero-Montejo, I. Estudio sobre sistemas meteorológicos que provocan eventos notables de precipitación en Cuba. Rev. Climatol. 2015, 15, 77-83.

18. Planos, E.O. Influencia de las grandes precipitaciones en la garantía de entrega de agua anual. Aqua-Lac 2015, 7, 38-48. [CrossRef]

19. Fernández-Alvarez, J.C.; Sorí, R.; Pérez-Alarcón, A.; Nieto, R.; Gimeno, L. The role of tropical cyclones on the total precipitation in Cuba during the hurricane season from 1980 to 2016. Atmosphere 2020, 11, 1156. [CrossRef]

20. Fernández, A.J.; Orbe, G.; Núñez, E. Eventos y patrones de precipitaciones extremas en la región central de Cuba. Rev. Cuba. Meteorol. 2008, 14, 32-44.

21. Burgos, Y.; González, I. Análisis de indicadores de extremos climáticos en la isla de Cuba. Rev. Climatol. 2012, 12, 81-90.

22. González-García, I.T.; Barcia-Sardiñas, S.; Hernández-González, D. Climatic Extremes Index in the Isla de la Juventud. Rev. Cuba. Meteorol. 2017, 23, 217-225.

23. Ramos, A.M.; Trigo, R.M.; Liberato, M.L.R.; Tomé, R. Daily precipitation extreme events in the Iberian Peninsula and its association with atmospheric rivers. J. Hydrometeorol. 2015, 16, 579-597. [CrossRef]

24. Ramos, A.M.; Martins, M.J.; Tomé, R.; Trigo, R.M. Extreme Precipitation Events in Summer in the Iberian Peninsula and Its Relationship with Atmospheric Rivers. Front. Earth Sci. 2018, 6, 110. [CrossRef]

25. Insua-Costa, D.; Lemus-Canovas, M.; Miguez-Macho, G. Climatology and ranking of hazardous precipitation events in the western Mediterranean area. Atmos. Res. 2021, 255, 105521. [CrossRef] 
26. Archivado Desde el Original el 26 de Diciembre de 2020. Available online: http:/ / www.onei.cu/aec2014/01\%20Territorio.pdf (accessed on 24 April 2021).

27. Taylor, M.A.; Enfield, D.B.; Chen, A.A. Influence of the tropical Atlantic versus the tropical Pacific on Caribbean rainfall. J. Geophys. Res. 2002, 107, 3127. [CrossRef]

28. Álvarez, A.; Herrera, R.S.; Noda, A.C.; Díaz, L. Comportamiento de las precipitaciones en el Instituto de Ciencia Animal en Cuba durante el período 1970-2009, como base para el manejo estratégico de los pastos. Rev. Cuba. Cienc. Agríc. 2012, 46, 301-307.

29. Cabrera, J.A.; Zuaznábar, R. The impact of sugarcane monoculture with pre-harvest burning and nitrogen fertilization on the environment. I. Carbon balance. Cultiv. Trop. 2010, 31, 5-13.

30. Lehner, B.; Verdin, K.; Jarvis, A. New global hydrography derived from spaceborne elevation data. Eos Trans. AGU 2008, 89, 93-94. [CrossRef]

31. Cutié, V. La Sequía en Cuba, un Texto de Referencia. Proyecto, no. 1/OP-15/GEF; Instituto de Meteorología: La Habana, Cuba, 2013; Volume 358.

32. Lecha, L.B.; Paz, L.; Lapinel, B. The Climate of Cuba; Editorial Academia: La Habana, Cuba, 1994; p. 186. ISBN 9590200060.

33. Beck, H.E.; Wood, E.F.; Pan, M.; Fisher, C.K.; Miralles, D.G.; Van Dijk, A.I.J.M.; McVicar, T.R.; Adler, R.F. MSWEP V2 Global 3-hourly $0.1^{\circ}$ precipitation: Methodology and quantitative assessment. Bull. Am. Meteorol. Soc. 2019, 100, 473-500. [CrossRef]

34. Centella-Artola, A.; Bezanilla-Morlot, A.; Taylor, M.A.; Herrera, D.A.; Martinez-Castro, D.; Gouirand, I.; Sierra-Lorenzo, M.; Vichot-Llano, A.; Stephenson, T.; Fonseca, C.; et al. Evaluation of sixteen gridded precipitation datasets over the Caribbean region using gauge observations. Atmosphere 2020,11, 1334. [CrossRef]

35. Beck, H.E.; Van Dijk, A.I.J.M.; Levizzani, V.; Schellekens, J.; Miralles, D.G.; Martens, B.; De Roo, A. MSWEP: 3-hourly 0.25 global gridded precipitation (1979-2015) by merging gauge, satellite, and reanalysis data. Hydrol. Earth Syst. Sci. 2017, $21,589-615$. [CrossRef]

36. Hersbach, H.; Bell, B.; Berrisford, P.; Hirahara, S.; Horányi, A.; Muñoz-Sabater, J. The ERA5 global reanalysis. Q. J. R. Meteorol. Soc. 2020, 146, 1999-2049. [CrossRef]

37. Landsea, C.W.; Franklin, J.L. Atlantic hurricane database uncertainty and presentation of a new database format. Mon. Weather Rev. 2013, 141, 3576-3592. [CrossRef]

38. Atlantic Hurricane Database (HURDAT2) 1851-2019. Available online: https://www.nhc.noaa.gov/data/\#hurdat (accessed on 10 May 2020).

39. Dunn, R.J.H.; Alexander, L.V.; Donat, M.G.; Zhang, X.; Bador, M.; Herold, N.; Lippmann, T.; Allan, R.; Aguilar, E.; Barry, A.A.; et al. Development of an updated global land in situ-based data set of temperature and precipitation extremes: HadEX3. J. Geophys. Res. Atmos. 2020, 125, e2019JD032263. [CrossRef]

40. Everitt, B.S.; Landau, S.; Leese, M. Cluster Analysis, 4th ed.; Arnold: London, UK, 2001.

41. Kaufman, L.; Rousseeuw, P.J. Finding Groups in Data: An Introduction to Cluster Analysis; Wiley Online Library: Hoboken, NJ, USA, 2005; ISBN 978-0-471-73578-6. [CrossRef]

42. Corporal-Lodangco, I.L.; Richman, M.B.; Leslie, L.M.; Lamb, P.J. Cluster analysis of north atlantic tropical cyclones. Procedia Comput. Sci. 2014, 36, 293-300. [CrossRef]

43. Chadee, X.T.; Clarke, R.M. Daily near-surface large-scale atmospheric circulation patterns over the wider Caribbean. Clim. Dyn. 2015, 44, 2927-2946. [CrossRef]

44. Relieve de Cuba. Available online: https://www.ecured.cu/Relieve_de_Cuba (accessed on 11 July 2021).

45. Bivariate ENSO Time Series or the "BEST" ENSO Index. Available online: https://psl.noaa.gov/people/cathy.smith/best/ (accessed on 9 July 2021).

46. Jury, M.; Malmgren, B.A.; Winter, A. Subregional precipitation climate of the Caribbean and relationships with ENSO and NAO. J. Geophys. Res. 2007, 112, D16107. [CrossRef]

47. What Is ENSO. Available online: https:/ / www.weather.gov/mhx/ensowhat (accessed on 9 July 2021).

48. Canesoltas, M. El frente de la brisa de Tierra. Rev. Cuba. Meteorol. 2002, 9, 83-89.

49. Juckes, M.; Smith, R.K. Convective destabilization by upper-level troughs. Q. J. R. Meteorol. Soc. 2020, 126, 111-123. [CrossRef]

50. Willoughby, H.E. Tropical cyclone eye thermodynamics. Mon. Weather Rev. 1998, 126, 3053-3067. [CrossRef] 